\title{
Sistem Informasi Penunjang Proses Pemesanan dan Desain Kue Pada Toko Kue Artisan Online Berbasis Web
} \author{
taniajovita@yahoo.com \\ suryasari.fik@uph.edu \\ arnold.aribowo@uph.edu \\ andree.widjaja@uph.edu \\ Diterima 22 Februari 2019 \\ Disetujui 24 Juni 2019
}

Tania Jovita Wibowo ${ }^{1}$, Suryasari $^{2}$, Arnold Aribowo ${ }^{3}$, Andree E. Widjaja ${ }^{4}$

Program Studi Sistem Informasi, Fakultas Ilmu Komputer, Universitas Pelita Harapan, Tangerang, Indonesia

\begin{abstract}
Along with the development of times, artisan cakes are increasingly in demand by the public to celebrate special days or as a gift. Online artisan cake is a cake shop that uses social media like Instagram and Facebook to sell their cakes. The current cake ordering process is still done manually through two stages. First, customer sees and chooses the type and design of cakes through Instagram or Facebook. Second, he or she places an order on the selected cake via Line or WhatsApp. The need of two different media would make the ordering system is less efficient. Apart from that, customer who wants to make special or custom requests can only make their requests only by personal messages via Line or WhatsApp, so there are often misunderstanding as well as inaccuracies caused by either customer or cake maker due to the different perspectives with regard to the customized pictures. Therefore, an information system is needed to support the order process and cake design at online artisan cake shops using Rapid Application Development (RAD) system development using prototyping. System modeling was developed by using UML 2.5, namely use case diagrams, activity diagrams, class diagrams and entity relationship diagrams. The final result of this research is a functional website that supports the ordering process and cake design at online artisan cake shops. This new system can simplify the ordering process and order customization on the design of the ordered cakes. The website was properly tested and thus is ready to be implemented.
\end{abstract}

Index Terms - Artisan Cake, RAD, Prototyping, PHP, UML 2.5

\section{PENDAhULUAN}

Seiring dengan berkembangnya zaman, kue artisan semakin banyak diminati oleh masyarakat untuk merayakan hari-hari spesial maupun sebagai hadiah. Sebutan artisan sendiri ditujukan kepada seseorang yang memiliki kemampuan dalam menerapkan seni dan kerajinan tangan, untuk menghasilkan suatu produk khusus berkualitas tinggi dan dalam jumlah yang terbatas [1]. Proses pembuatan kue artisan ini seringkali dilakukan menggunakan tangan atau metode tradisional. Kue artisan online sendiri merupakan toko kue yang memanfaatkan sosial media seperti Instagram dan Facebook untuk menjual kue-kuenya.

Berdasarkan observasi yang penulis sudah lakukan, proses pemesanan kue artisan pada toko kue umumnya masih dilakukan secara manual, di mana pemesanan dilakukan melalui dua tahap. Tahap pertama dilakukan dengan melihat dan memilih jenis dan desain kue melalui Instagram atau Facebook. Selanjutnya, tahap kedua dilakukan setelah kue sesuai dengan keinginan, maka akan dilakukan pemesanan melalui Line atau WhatsApp. Dibutuhkannya dua media yang berbeda menjadikan sistem pemesanan kurang efisien. Selain itu, saat ini pelanggan hanya bisa mengajukan permintaan khusus untuk mengubah desain dan penempatan hiasan ataupun tulisan yang diinginkan melalui permintaan personal melalui pesan, sehingga sering terjadi kesalah-pahaman dan ketidaktepatan permintaan antara pelanggan dan pembuat kue yang umumnya dikarenakan keduanya kurang mendapatkan gambaran yang jelas dari permintaan yang diinginkan. Kendala yang dihadapi dari pesanan khusus atau custom yaitu berhubungan dengan perubahan desain dan kedua pihak yang tidak dapat melihat visualisasi dari permintaan atau ide yang diminta, sehingga menyebabkan perbedaan pemikiran.

Saat pembuat kue artisan akan membuat kue, secara tidak langsung mereka melakukan visual thinking. Visual thinking adalah konsep yang lahir dari melihat masalah dari berbagai sudut pandang, memikirkan alternatif solusi, menggambar sketsa, dan menggerakkan tangan secara komprehensif hingga masalah terselesaikan [2-5]. Aplikasi online yang ada saat ini seperti Canva [6], dapat digunakan untuk membuat desain sederhana yang juga menyediakan fitur template. Saat menggunakan Canva, pengguna secara langsung menerapkan visual thinking dengan membuat desain yang diharapkan hingga masalah 
terselesaikan. Namun sayangnya, Canva belum dapat menyelesaikan masalah yang ada, dikarenakan Canva sendiri tidak spesifik dikembangkan untuk toko kue artisan, di mana sistem dapat mempertemukan pembuat kue artisan dan pembeli untuk memvisualisasikan pesanan secara langsung di dalam sistem.

Oleh karena itu, tujuan utama dari penelitian ini adalah untuk mengembangkan sebuah sistem informasi spesifik berbasis web yang dapat menunjang proses pemesanan dan desain kue berdasarkan teori visual thinking yang disinggung sebelumnya, pada toko kue artisan. Sistem yang dikembangkan ini diharapkan akan memudahkan sistem pemesanan kue artisan sehingga proses bisnis pada toko kue dapat lebih dilakukan dengan lebih efektif dan efisien. Selain itu, toko kue yang pemesanannya memanfaatkan teknologi berbasis web dapat memperoleh keuntungan kompetitif yang tidak dimiliki oleh toko-toko kue artisan lainnya.

\section{A. System Development Life Cycle (SDLC)}

System Development Life Cycle adalah serangkaian proses yang digunakan untuk memahami bagaimana sistem informasi dapat membantu proses bisnis melalui perancangan, pengembangan, dan menyampaikan sistem yang dikembangkan tersebut kepada pengguna [7]. Dalam SDLC, terdapat empat fase utama, yaitu tahap perencanaan (planning), analisis (analysis), desain (design) dan implementasi (implementation) [7].

\section{B. Rapid Application Development (RAD)}

Rapid Application Development (RAD) adalah metode pengembangan sistem yang melakukan penyesuaian pada proses SDLC, agar waktu pembangunan sistem menjadi lebih singkat [7]. Salah satu metode RAD yaitu prototyping, di mana metode ini akan mempermudah pengguna untuk mengetahui sistem yang dibangun dan memberikan masukkan serta perbaikan jika sistem yang dikembangkan belum memenuhi kebutuhan pengguna.

\section{Unified Modeling Language 2.5 (UML 2.5)}

Unified Modeling Language (UML) adalah standar penggambaran diagram yang telah disetujui oleh Object Management Group (OMG) pada tahun 1997 untuk membuat pemodelan proyek pengembangan sistem mulai dari tahap analisis hingga implementasi [7]. Pemodelan UML memiliki fokus aturan-aturan bahasa yang bertujuan untuk menampilkan sistem secara fungsional dan struktural. Versi yang akan digunakan dalam penelitian ini yaitu UML versi 2.5 Diagram UML 2.5 dan pemodelan sistem akan menggunakan activity diagram, use case diagram, dan class diagram [7].

\section{Relational Database Management System} (RDBMS)

Relational Database Management System (RDBMS) adalah piranti lunak yang digunakan untuk mengelola sistem basis data, dengan entitas utama yang terdiri dari tabel-tabel yang saling memiliki relasi [8]. Tabel penyimpanan data dalam RDBMS menggunakan tabel yang terdiri dari kumpulan entri data yang di dalamanya terdiri dari banyak kolom dan baris. Di dalam setiap tabel terdapat kode unik yang disebut primary key, dan saat tabel itu berhubungan dengan tabel lain akan berubah menjadi foreign key. Data akan tersimpan dalam satu tabel dan data tersebut dapat diakses atau diambil oleh tabel lain menggunakan foreign key [9].

\section{E. JavaScript}

JavaScript adalah bahasa yang membuat elemen dalam halaman website dapat bekerja dan digunakan untuk memanipulasi elemen pada halaman web, gaya yang diterapkan, atau bahkan browser itu sendiri [10]. JavaScript juga menambahkan perilaku (behaviors), interaktivitas (interactivity), dan fungsionalitas (functionality) ke dalam elemen di dalam halaman web dan bahkan ke jendela browser itu sendiri [10].

\section{F. Hypertext Preprocessor (PHP)}

HTML adalah bahasa yang digunakan untuk membuat isi dokumen halaman web. Tetapi HTML bukanlah bahasa pemrograman, melainkan bahasa markup yang adalah sistem untuk mengidentifikasi dan menjelaskan berbagai komponen dokumen seperti headings, paragraf, dan daftar. Markup menunjukkan struktur dasar dokumen [10]. Di dalam HTML terdapat Cascading Style Sheets (CSS) yang mendeskripsikan bagaimana tampilan atau presentasi dari konten, seperti fonts, warna, gambar latar belakang, spasi baris, dan susunan halaman [11].

\section{G. Perancangan Antarmuka Berbasis Web}

Dalam perancangan sistem berbasis web, terdapat beberapa faktor yang perlu diperhatikan dalam perancangan antarmuka suatu website [12]. Interface design meliputi struktur dasar dan bagaimana organisasi dari user interface, screen layout, dan navigasi. Interface design merupakan hal yang penting sebab user interface memberikan kesan pertama bagi sebuah website [13-14].

\section{H. Eight Golden Rules of Interface Design}

Eight Golden Rules of Interface Design adalah kumpulan prinsip atau aturan dalam membuat sistem yang interaktif dan rancangan antarmuka pada suatu sistem atau aplikasi. Rules ini diciptakan oleh Ben Shneiderman, seorang ahli dalam interface design komputer [13]. 


\section{Visual Thinking}

Visual thinking adalah konsep yang lahir dari melihat masalah dari berbagai sudut pandang, memikirkan alternatif solusi, menggambar sketsa, dan menggerakkan tangan secara komprehensif hingga masalah terselesaikan [2]. Meskipun visual thinking dapat terjadi terutama dalam konteks melihat, atau hanya dalam imajinasi, atau sebagian besar dengan pensil dan kertas, visual thinking yang ahli secara fleksibel menggunakan dan menemukan bahwa melihat, membayangkan, dan menggambar itu bersifat interaktif (interactive imagery) [3-5].

\section{J. Belanja Online (Online Shopping)}

Belanja Online (Online Shopping) adalah proses belanja yang dilakukan konsumen dengan penjual secara interaktif dan real-time melalui internet, tanpa harus bertatap muka secara langsung [15]. Online shop atau toko online adalah proses mejual barang dan jasa melalui internet, tanpa harus ada toko fisik [16]. Jadi belanja online adalah proses jual-beli barang, dan jasa yang dilakukan secara online tanpa bertemu langsung antara penjual dan pembeli atau datang langsung ke toko.

\section{K. Pengujian Sistem (Testing)}

Pengujian sistem (testing) diperlukan agar dapat memastikan sistem berjalan sesuai dengan prosedur yang seharusnya [7]. Pengujian sistem adalah proses menemukan dan memperbaiki errors dengan cara menjalankan sistem tersebut. Tujuan dilakukan pengujian adalah untuk mengidentifikasi masalah yang bisa terjadi. Pada penelitian ini metode pengujian yang akan digunakan adalah unit testing dengan pendekatan black box testing. Black box testing adalah metode pengujian yang dilakukan tanpa harus mengetahui source code atau programming codes dari aplikasi. Penguji hanya perlu mengetahui input, output, requirement sistem, dan bagaimana sistem bekerja secara umum sehingga dapat dilakukan verifikasi apakah input dan output sudah benar, tanpa harus memikirkan bagaimana sistem memprosesnya [7].

\section{Metodologi Penelitian}

Dalam melakukan penelitian ini, ada beberapa tahap metodologi penelitian yang dipakai untuk mengumpulkan data yaitu:

\section{A. Metode Pengumpulan Data}

Dalam penyusunan penelitian ini, metode pengumpulan data yang digunakan untuk membantu pengembangan sistem yaitu:

- Melakukan wawancara langsung dengan pembuat kue artisan untuk mengetahui proses pemesanan secara keseluruhan dan kendala yang dihadapi.
- Melakukan survei kepada pelanggan kue artisan untuk mengetahui kebutuhan akan sistem yang akan dibangun.

- Pengumpulan data yang dilakukan secara langsung dengan mempelajari proses pemesanan toko kue artisan online.

- Melakukan studi literatur untuk metode pengembangan sistem, sehingga sesuai dengan kebutuhan sistem yang akan dibangun dan dapat diterapkan dengan baik saat pengembangan sistem dilakukan.

\section{B. Metode Pengembangan Sistem}

Metode pengembangan sistem yang digunakan adalah metode RAD (Rapid Application Development) dengan metode prototyping [7]. Metode ini membutuhkan interaksi antara pengembang dan pengguna untuk pengembangan sistemnya untuk memastikan tujuan pembuatan sistem sesuai dengan kebutuhan pengguna. Dalam metode prototyping proses analisis, perancangan dan implementasi dilakukan secara bersamaan dan berulang hingga didapatkan model terbaik yang akan digunakan di sistem [7].

Di dalam fase analisis dikumpulkan kebutuhan awal (requirements) pengguna sebagai dasar untuk perancangan sistem. Kemudian dilanjutkan ke tahap perancangan dan implementasi, dimana pada tahap ini dibuatkan desain awal (prototype) yang berupa rancangan antar muka untuk kemudian ditunjukkan kepada pengguna agar mendapatkan gambaran awal apakah sistem yang dirancang sudah memenuhi ekspektasi pengguna atau belum. Ketika desain sudah disetujui oleh pengguna, maka dilanjutkan pemberian coding ke dalam prototype tersebut. Selama fase perancangan dan implementasi, pengguna dilibatkan untuk memberikan masukkan terhadap prototype yang sedang dibangun, jika ada masukkan atau saran maka prototype tersebut diperbaiki lagi sampai memenuhi ekspektasi dan kebutuhan pengguna.

Pemilihan metode ini (prototyping) dikarenakan pentingnya keterlibatan pengguna dan waktu pengembangan sistem yang singkat. Hasil desain sistem yang telah disetujui pengguna akan dikembangkan dan diimplementasikan sehingga menjadi suatu sistem informasi yang dapat mendukung proses pemesanan berbasis web yang ada di toko kue artisan online.

\section{HASIL DAN PEMBAHASAN}

\section{A. Tahap Analisis}

Use Case Diagram berdasarkan notasi UML yang digunakan pada sistem informasi penunjang pemesanan dan desain kue pada toko kue artisan online berbasis web dapat dilihat pada Gambar 1 


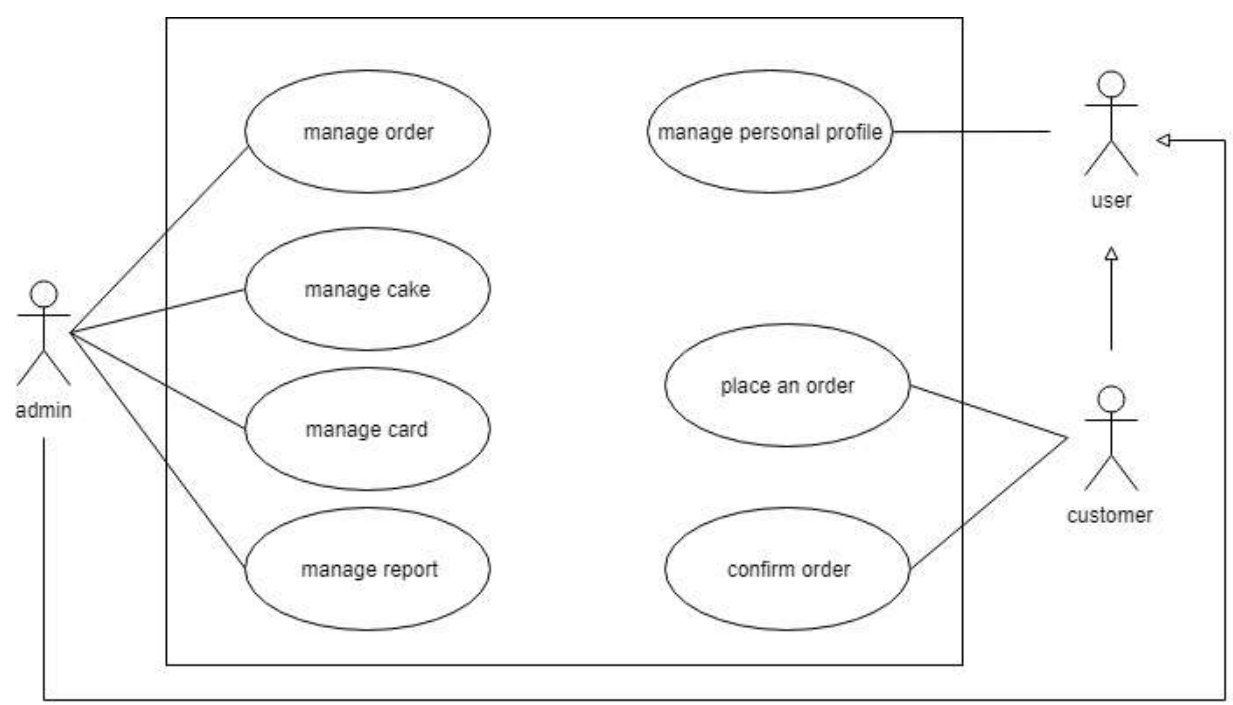

Gambar 1. Use Case Diagram Sistem Informasi Penunjang Pemesanan dan Desain Kue pada Toko Kue Artisan Online Berbasis Web
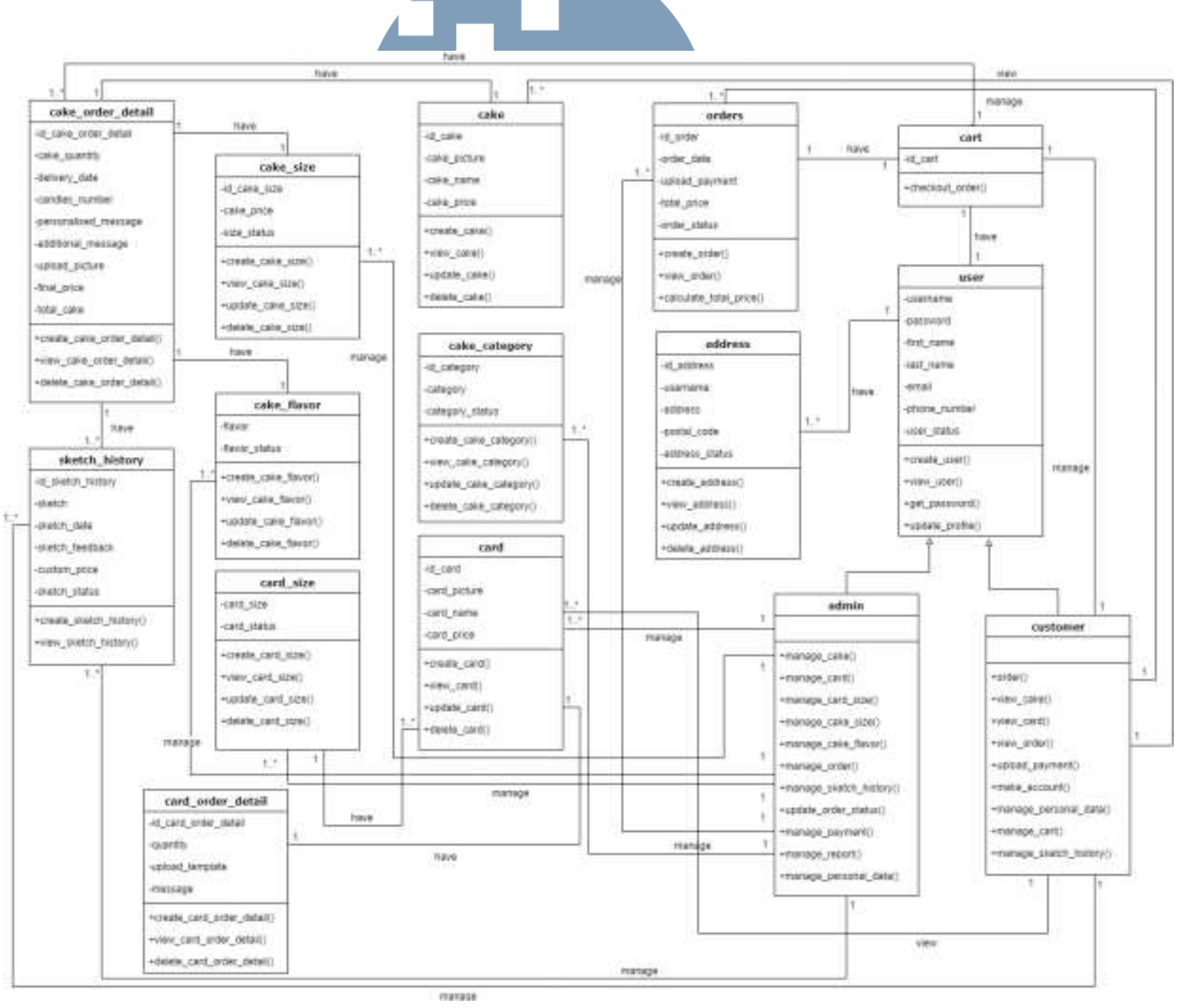

Gambar 2. Class Diagram Sistem Informasi Penunjang Pemesanan dan Desain Kue Pada Toko Kue Artisan Online Berbasis Web 
Class Diagram pada sistem informasi penunjang pemesanan dan desain kue pada toko kue artisan online berbasis web dapat dilihat pada Gambar 2.

\section{B. Tahap Perancangan}

4.1 Perancangan Manajemen Data (Database)

Perancangan Manajemen Database yang digunakan dalam penelitian ini adalah Entity Relationship Diagram (ERD). Perancangan manajemen data dari Sistem Informasi Penunjang Pemesanan dan Desain Kue Pada Toko Kue Artisan Online Berbasis Web dapat dilihat pada Gambar 3.

4.2 Perancangan Lapisan Antarmuka
Fungsi utama sistem ini yaitu untuk membantu pelanggan melakukan pemesanan kue dan kartu, serta memvisualisasikan pesanan kue pesanan khusus (custom) yang diinginkan, serta untuk pemilik toko kue dapat memberikan gambaran sederhana berupa sketch kepada pelanggan. Fungsi utama dari sistem ini dapat dilihat pada Gambar 4.

\subsection{Pengujian dan Implementasi}

\section{Scenario Setup:}

- Karyawan Toko Kue XYZ sudah $\log$ in ke dalam sistem.

- Karyawan Toko Kue XYZ memilih menu order.

- Karyawan Toko Kue XYZ memilih detail.

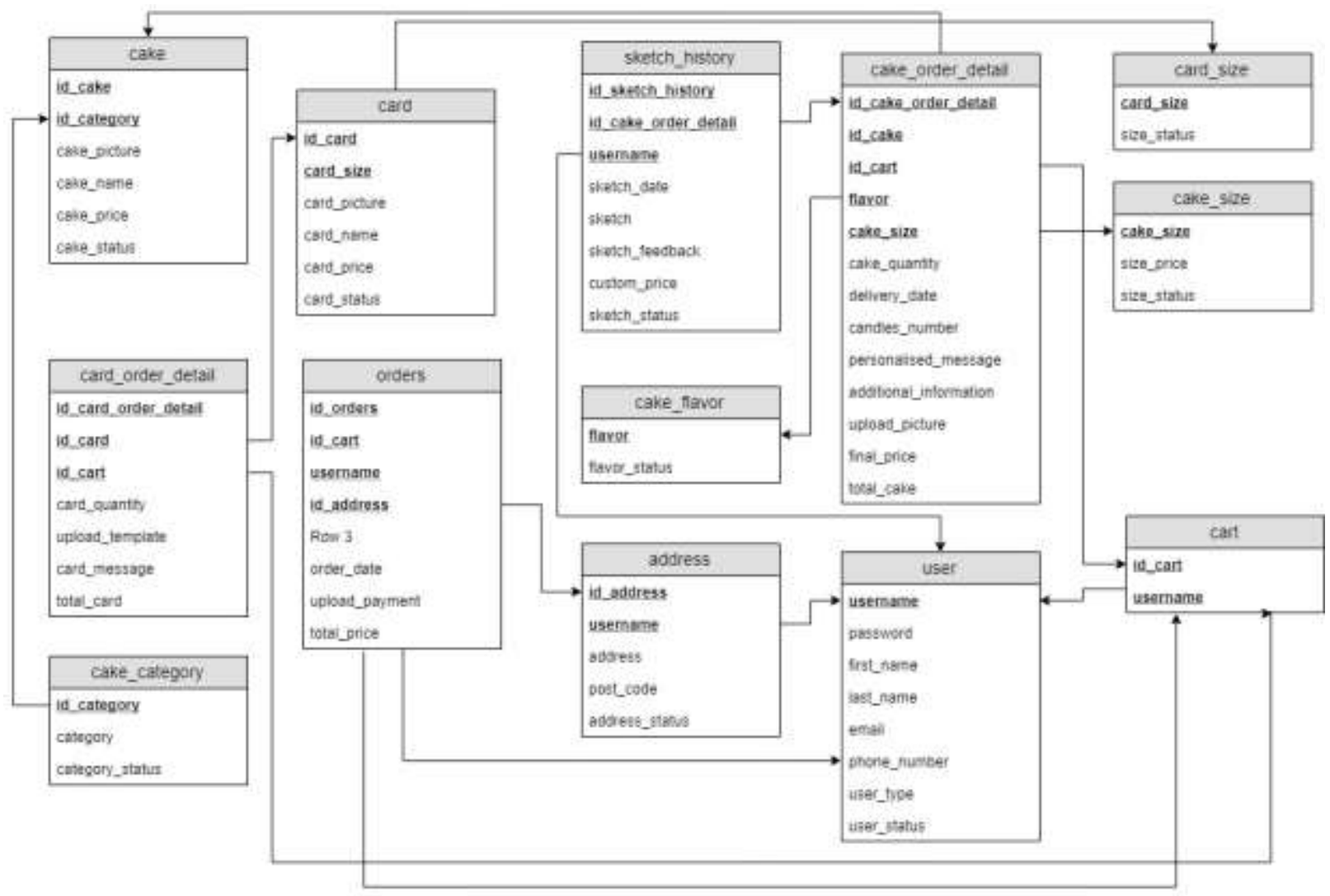

Gambar 3. Entity Relationship Diagram Sistem Informasi Penunjang Pemesanan dan Desain Kue Pada Toko Kue Artisan Online Berbasis Web 


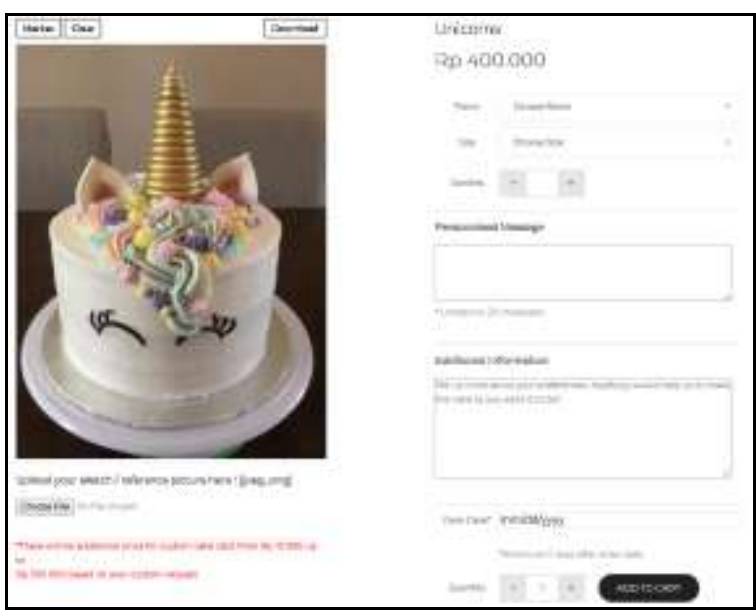

Gambar 4. Form Pemesanan Kue Kustom

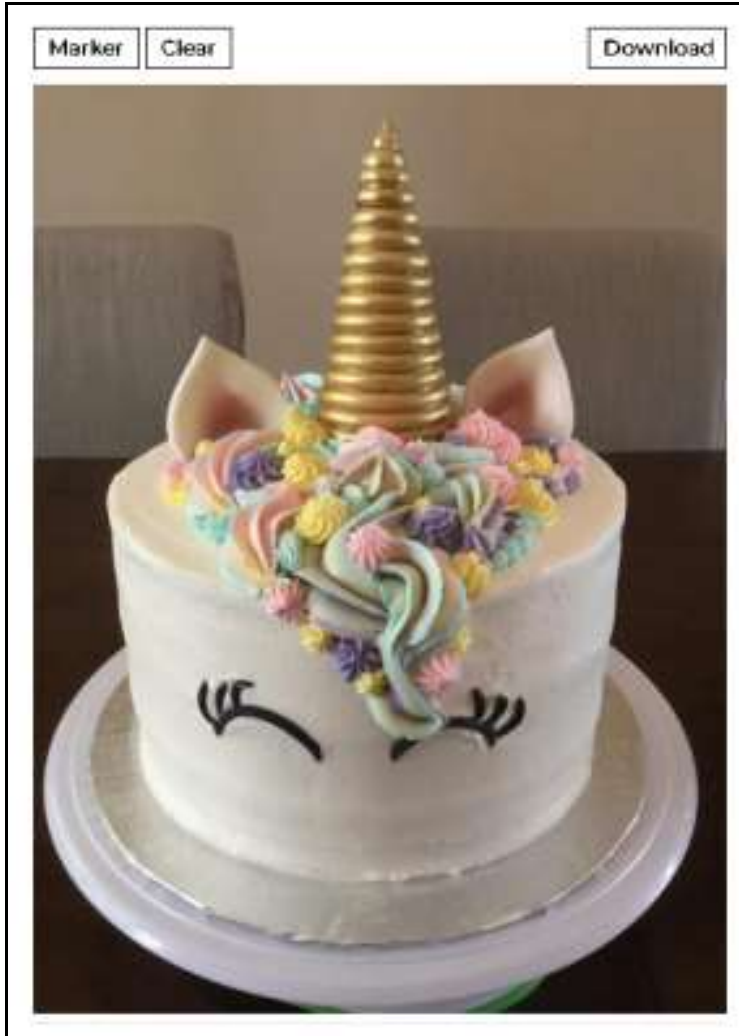

Gambar 5. Fitur Sketch Marker, Clear, dan Download

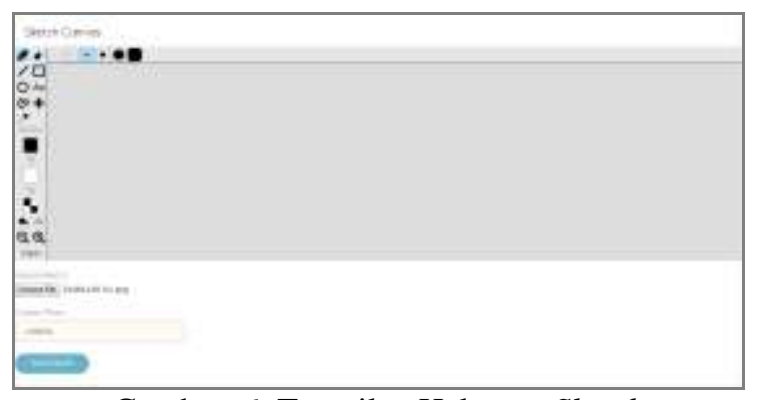

Gambar 6. Tampilan Halaman Sketch
Tabel 1. Test Case Membuat dan Menyimpan Sketch

\section{Test Number: 6}

Test Subject: Karyawan Toko Kue XYZ

Function: Membuat dan Menyimpan Sketch

\begin{tabular}{|c|c|c|c|}
\hline Scenario & Test Step & $\begin{array}{c}\text { Expected } \\
\text { Result }\end{array}$ & $\begin{array}{c}\text { Result } \\
(\mathrm{P} / \mathrm{F})\end{array}$ \\
\hline $\begin{array}{l}\text { Membuat } \\
\text { dan } \\
\text { menyimpan } \\
\text { sketch. }\end{array}$ & 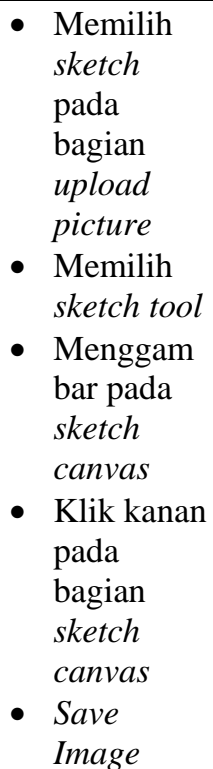 & $\begin{array}{l}\text { Menampi } \\
\text { lkan } \\
\text { sketch } \\
\text { canvas } \\
\text { dan } \\
\text { gambar } \\
\text { yang } \\
\text { dibuat. } \\
\text { Gambar } \\
\text { tersimpan } \\
\text { di dalam } \\
\text { komputer } \\
\text {. }\end{array}$ & $\mathrm{P}$ \\
\hline
\end{tabular}

\section{KESIMPULAN DAN SARAN}

A. Kesimpulan

Pengerjaan telah menghasilkan sebuah sistem untuk menunjang proses pemesanan dan desain kue pada toko kue artisan online yang ditujukan untuk membantu baik pemilik toko dan pembeli kue artisan online. Dengan adanya sistem ini, pembeli dapat melakukan proses pemesanan mulai dari memilih kue hingga melakukan pemesanan melalui satu sistem. Sistem ini juga membantu pembeli berkomunikasi dan menyampaikan keinginan maupun gambaran mengenai kue yang ingin di-custom menggunakan sketch tool yang terdapat pada sistem. Sistem ini telah dirancang sesuai dengan kebutuhan yang didapat dari hasil survey dan wawancara yang dilakukan kepada pelanggan kue artisan online dan pembuat kue yang berkerja pada toko kue artisan online.

Sistem informasi yang telah dikembangkan ini dapat membantu pemilik toko dalam memberikan proses pemesanan yang praktis dan efisien karena semua prosesnya dilakukan melalui satu sistem. Sistem ini juga membantu pemilik toko kue untuk memproses pemesanan kue kustom sehingga dapat mengurangi terjadinya kesalahan. Berdasarkan hasil 
pengujian (testing) yang telah dilakukan, sistem usulan ini telah lulus uji dan siap untuk diimplementasi. Dalam tahap pengujiannya sendiri telah dilakukan langsung oleh pihak toko kue dan pelanggan toko kue artisan online yang ingin melakukan pemesanan kue melalui sistem yang dikembangkan ini. Adapun sistem ini telah memenuhi kebutuhan pengguna, baik pihak toko kue maupun pelanggan toko kue dalam hal sebagai berikut:

- mempermudah pelanggan toko kue artisan online yang ingin melakukan pemesanan tanpa harus melalui lebih dari satu sistem yang berbeda dan tanpa adanya batasan waktu dan tempat;

- memberikan gambar sketch sesuai dengan permintaan dan gambaran yang diberikan pelanggan pada saat melakukan pemesanan kue kustom;

- memberikan wadah untuk toko roti untuk menyimpan data pembeli dan pemesanan tanpa harus melakukan pencatatan menggunakan sistem konvensional;

- memfasilitasi penyediaan laporan kegiatan pemesanan yang dilakukan oleh pelanggan toko roti artisan online, seperti laporan penjualan dan laporan detail pemesanan;

- memfasilitasi pelanggan untuk melakukan pemesanan dan menghubungi pihak toko kue;

- proses pemesanan menjadi lebih efektif dan efisien dengan adanya sistem. Hal ini dapat dilihat dari pembandingan proses pemesanan kue tanpa menggunakan sistem usulan yang dilakukan oleh toko kue. Pada saat toko kue masih menggunakan sistem lama, pada saat pelanggan melakukan pesanan toko kue harus membalas setiap pesanan melalui chat di aplikasi WhatsApp atau Line, dan mengajukan pertanyaan yang hampir sama pada setiap chat.

\section{B. Saran}

Sistem penunjang proses pemesanan dan desain kue pada toko kue artisan online ini merupakan langkah awal untuk meningkatkan kinerja toko kue dalam memberikan kemudahan bagi pelanggan untuk melakukan proses pemesanan terutama pesanan kue kustom. Terdapat peluang yang dapat dilakukan untuk mengembangkan sistem yang dapat dilakukan selanjutnya. Adapun saran yang dapat diusulkan untuk pengembangan selanjutnya adalah:
- mengembangkan gambaran sketch menjadi gambar 3 dimensi untuk lebih memperjelas dan memberikan gambaran yang lebih nyata dari pesanan kue pesanan khusus (custom) kepada pelanggan;

- menambahkan jenis laporan lain seperti laporan penjualan dari setiap produk yang dijual dari data pemesanan yang sudah ada untuk dapat dikelola oleh toko kue untuk meningkatkan kinerja toko kue dan hubungan antara toko kue dan pelanggan.

\section{DAFTAR PUSTAKA}

[1] E. Setiawan, Kamus Besar Bahasa Indonesia (KBBI), 2019. Online: https://kbbi.web.id/artisan [tanggal akses: 29 April 2019].

[2] R. H. McKim, Experiences in Visual Thinking, 4th Edition, Monterey, USA: Brooks-Cole, 1980.

[3] F. Olivia, Visual Thinking, Jakarta: Elex Media Komputindo, 2009.

[4] Z. Les, M. Les, Shape Understanding System: The First Steps toward the Visual Thinking Machines, Australia: Springer, 2008.

[5] J. Walny, S. Carpendale, N. Henry Riche, G. Venolia and P. Fawcett, "Visual Thinking In Action: Visualizations As Used On Whiteboards", IEEE Transactions on Visualization and Computer Graphics, vol. 17, no. 12, pp. 2508-2517, Dec. 2011.

[6] Canva, About Canva, 2019. Online: https://about.canva.com/ [tanggal akses: 29 April 2019].

[7] A. Dennis, B. H. Wixom and D. Tegarden, System Analysis \& Design: An Object-Oriented Approach with UML, 5 ed., Wiley, 2014.

[8] C. M. Coronel, S. Morris and P. Rob, Database Principles: Fundamentals of Design, Implementation, and Management; $9^{\text {th }}$ Edition (International Edition), USA: Cengage Learning, 2011.

[9] Arbie, Manajemen Database dengan MySQL, Yogyakarta: Penerbit ANDI, 2004.

[10] J. Niederst Robbins, Learning Web Design, $4^{\text {th }}$ Edition, California: O'Relly Media, 2012.

[11] C. Pitt, Pro PHP MVC, Apress, 2010.

[12] J. Preece, H. Sharp, Y Rogers, Interaction Design: Beyond Human-Computer Interaction $4^{\text {th }}$ Edition, New Jersey: Wiley, 2015.

[13] B. Shneiderman, C. Plaisant, Designing the User Interface: Strategies for Effective Human-Computer Interaction, 5th Edition, USA: Pearson, 2009.

[14] J. Sklar, Principles of Web Design $4^{\text {th }}$ Edition, Canada: Cengage Learning, 2009.

[15] Mujiyana, I. Elissa, “Analisis Faktor-Faktor Yang Mempengaruhi Keputusan Pembelian Via Internet Pada Toko Online", J@TI Undip, Vol VIII, No. 3, September 2013.

[16] Y. Wicaksono, Panduan Praktis Buka Usaha Dengan Modal Laptop, Jakarta: Elex Media Komputindo, 2010. 